\title{
ARCOS, PARÁBOLAS E FÁBULAS DE POVOS
}

\author{
Roberta Tojal’
}

A exposição "Arcos, parábolas e fábulas de povos", foi montada como parte da finalização do projeto de mestrado "Corpo, movimento e cultura: um estudo fotoetnográfico da imagem do arqueiro nos X e XI Jogos dos Povos Indígenas.". A autora propõe a montagem de pranchas com narrativas fotoetnográficas nas quais a figura do arqueiro faz a ligação entre as expressões de cinco diferentes povos que participaram dos $\mathrm{X}$ e XI Jogos dos Povos Indígenas.

A imagem do arqueiro é a chave que abre os pensamentos sobre como cada uma dessas etnias está comunicando sua história e sua cultura. O corpo do arqueiro e o fazer do arco e flecha testemunham e evidenciam os dizeres étnicos e as falas políticas do seu povo. Deste modo, as sequências de imagens comunicam mais do que o instante registrado, a forma como estes povos apresentam sua alteridade num ambiente alien no qual são protagonistas.

A cada dois anos, uma arena é montada no ambiente urbano para receber cerca de 1.200 indígenas vindos das mais diversas regiões do Brasil, para celebrarem os Jogos dos Povos Indígenas. Eles representam 40 dos 234, diferentes povos que vivem em território brasileiro e trazem consigo artefatos, adornos, línguas e modos de vida distintos e únicos. Durante sete dias, essa arena será palco das apresentações de suas práticas corporais, e a própria cidade será cenário de um intenso intercâmbio cultural Os Jogos ocupam cinco diferentes espaços, sendo eles: a arena, o fórum social indígena, a feira de artesanato, o campo de futebol, uma área de água (rio, praia, lago).

1 Mestre em Educação Física/Unicamp - Membro do Comitê Intertribal de Memoria e Giência Indígena. 


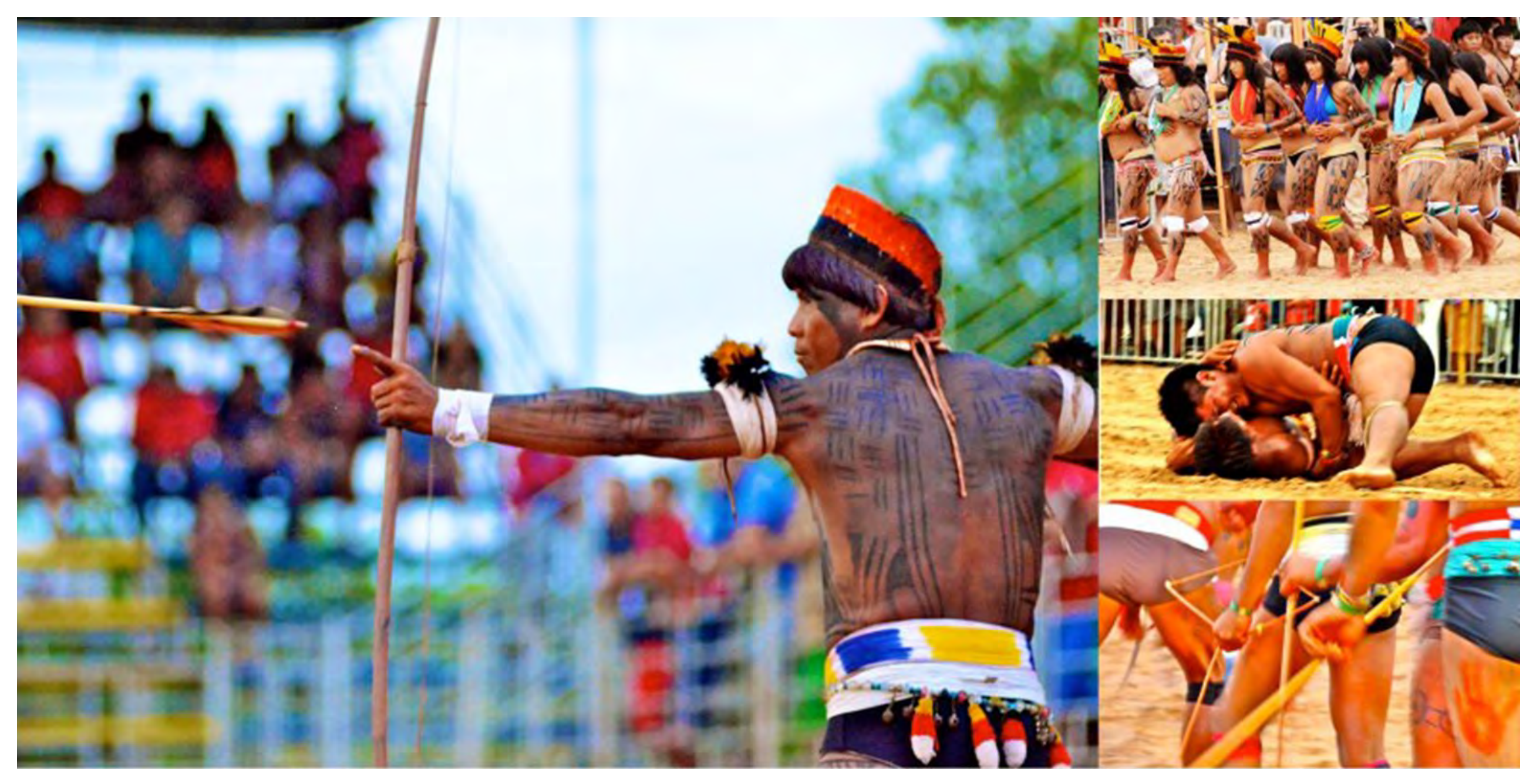

Kamayura 


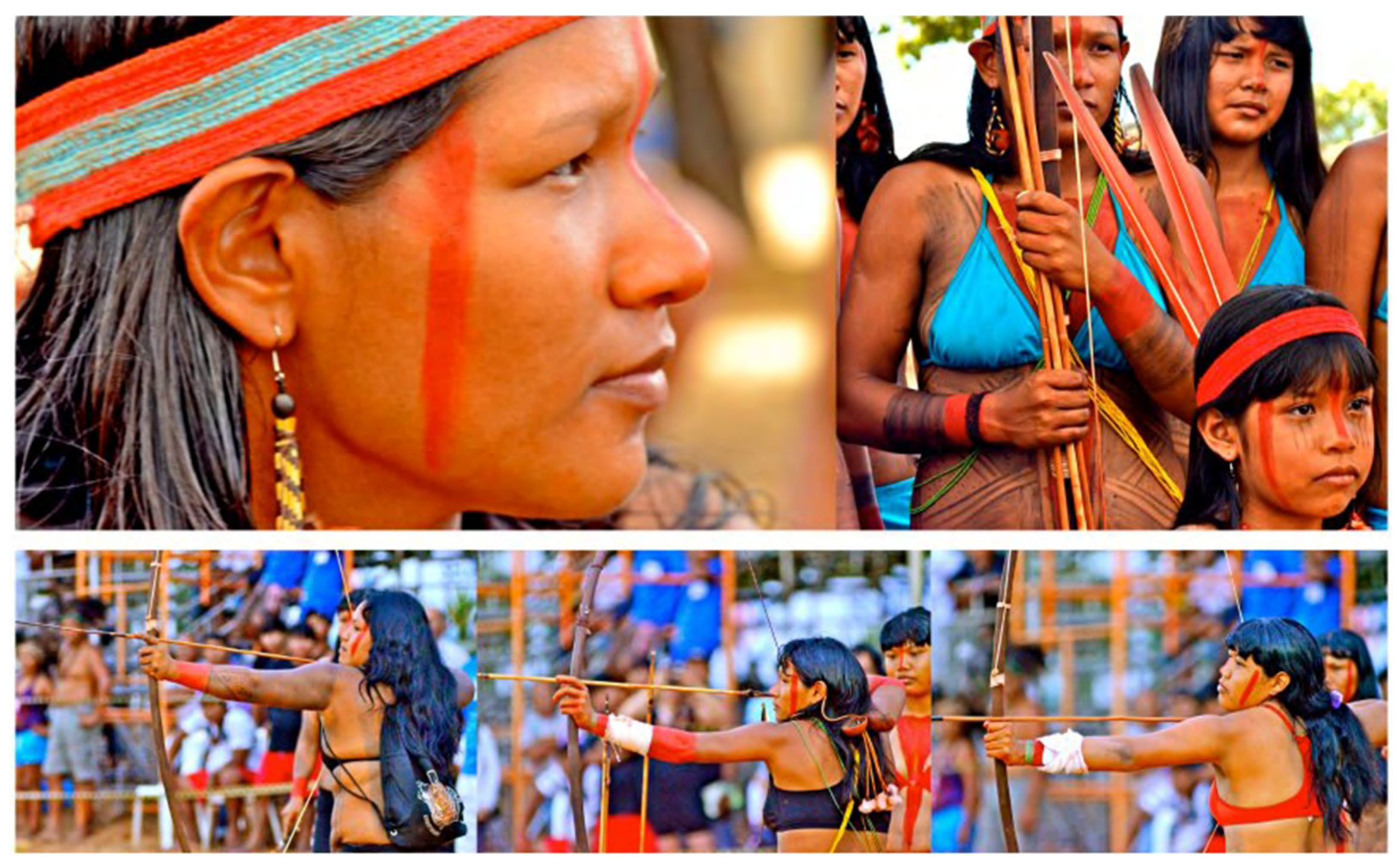




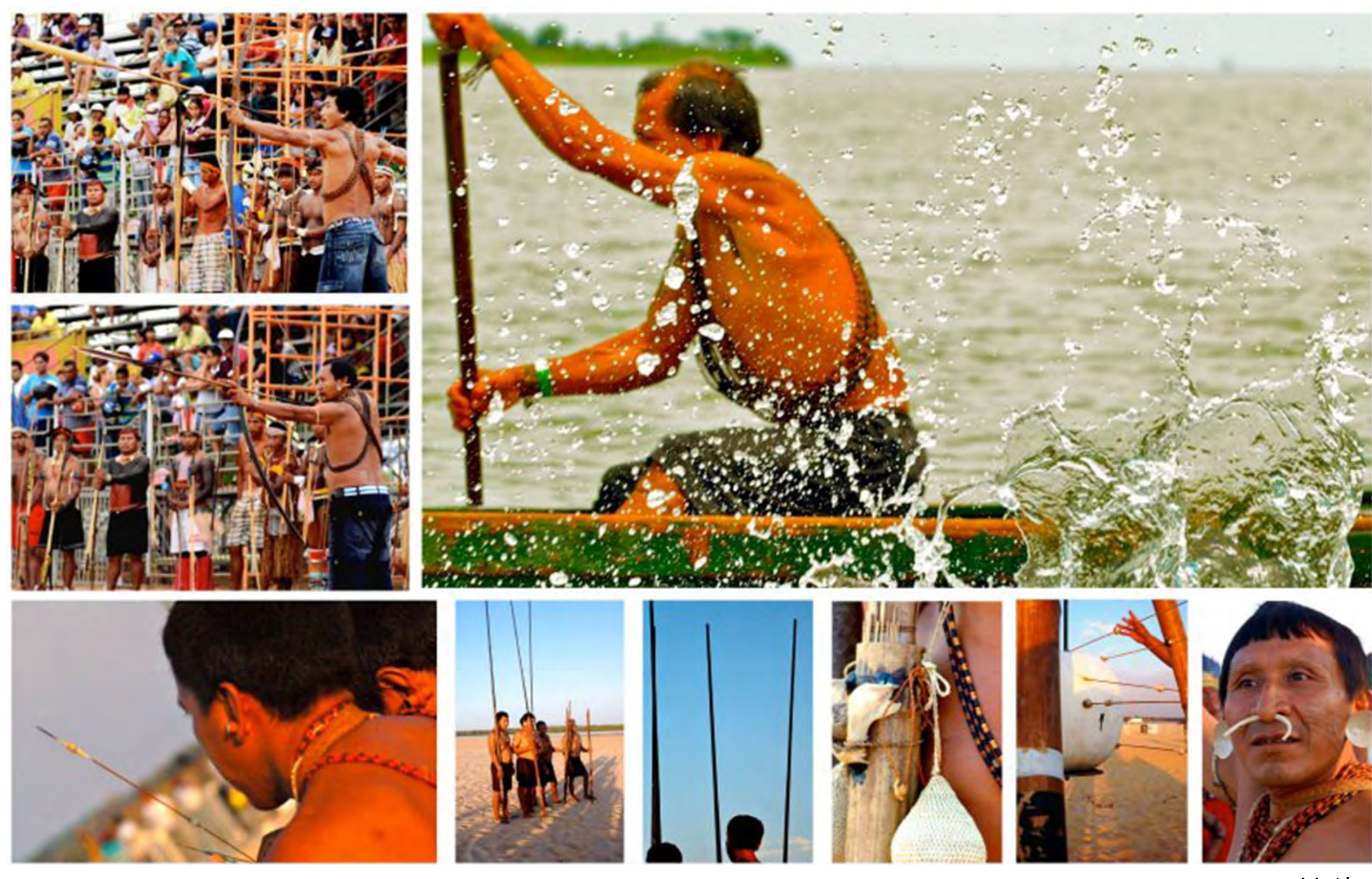



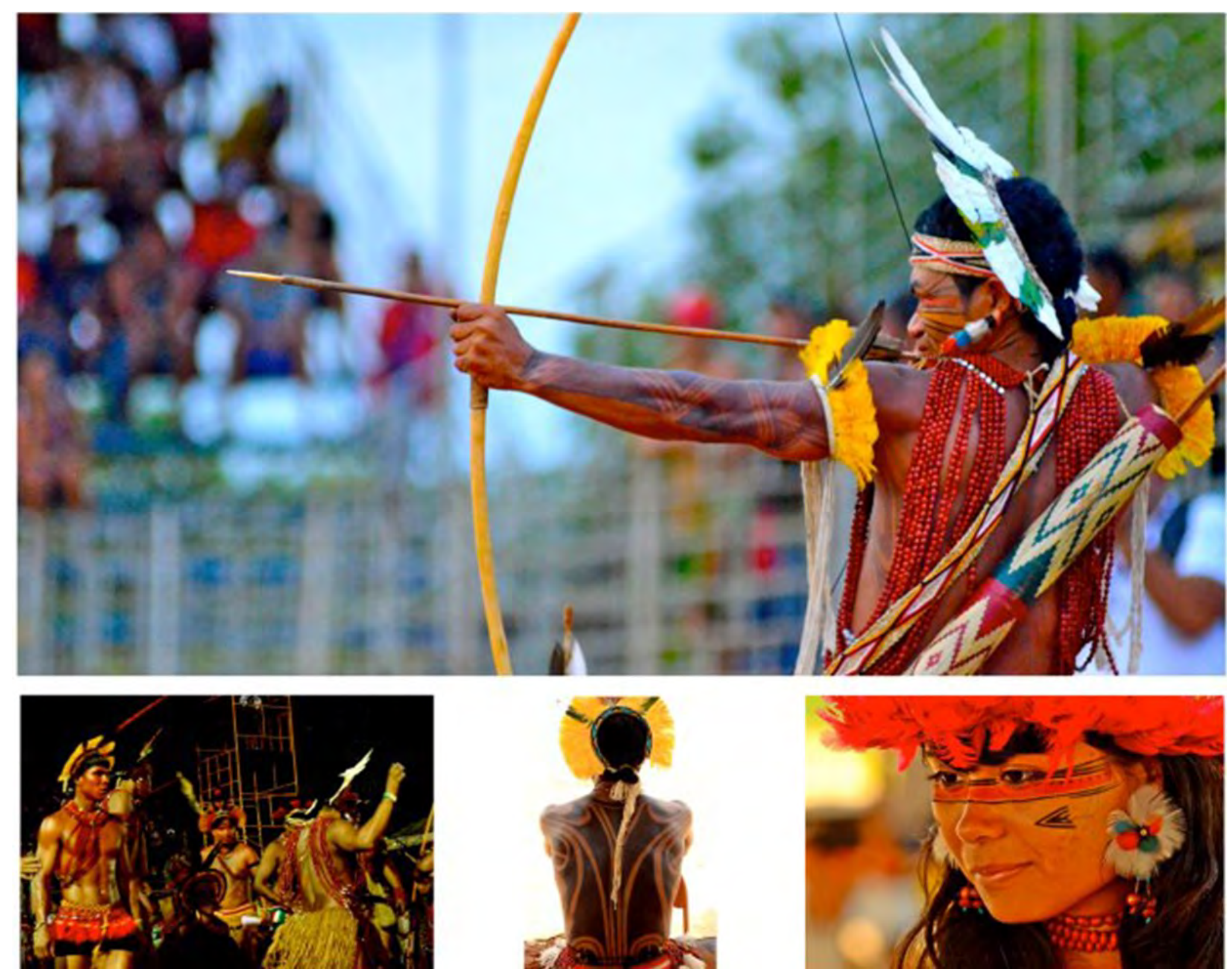

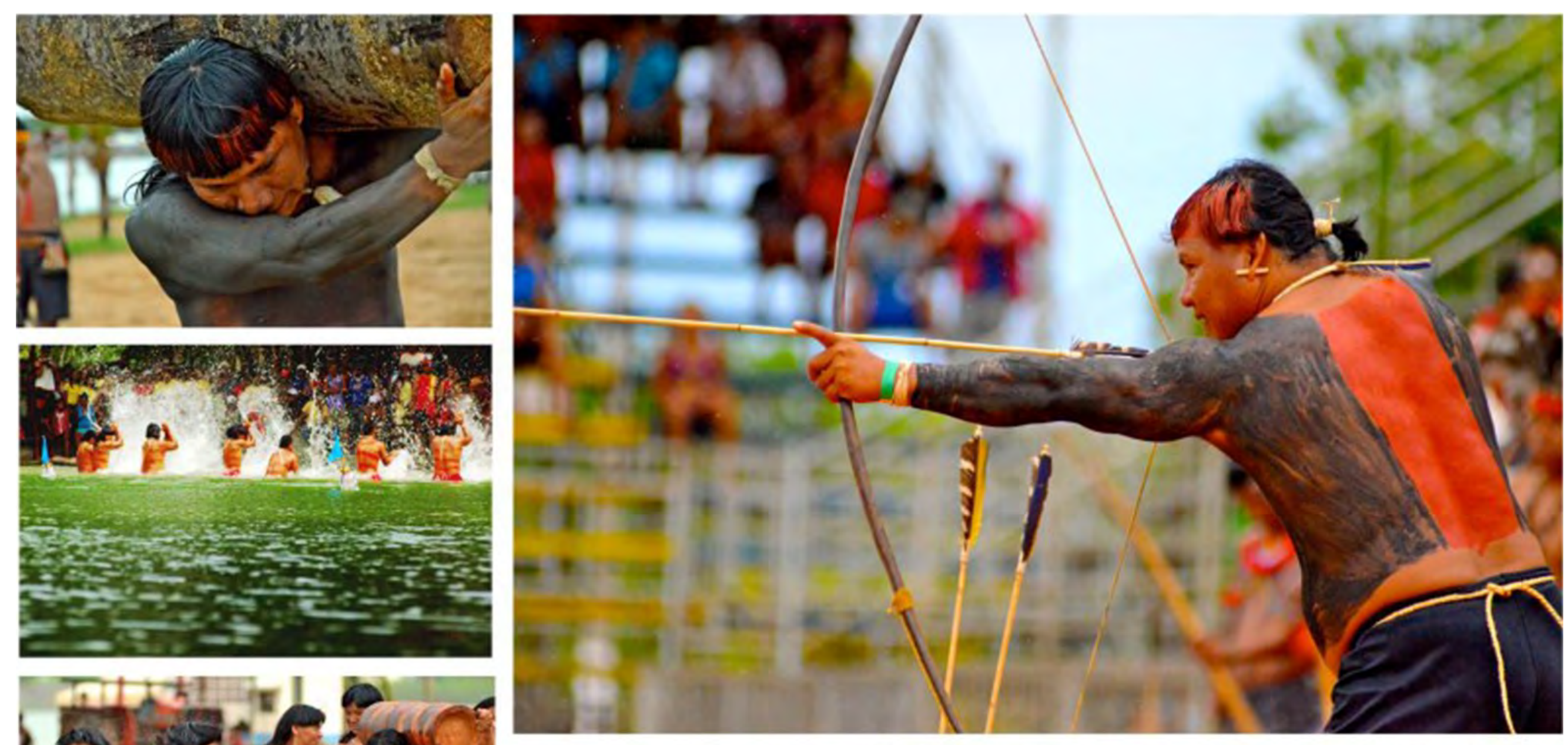

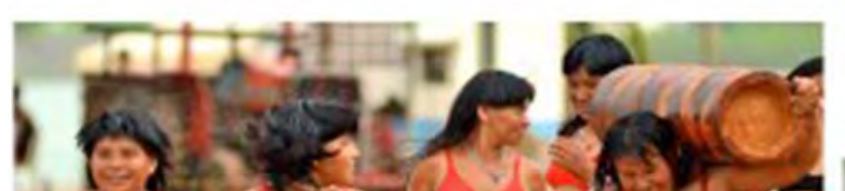
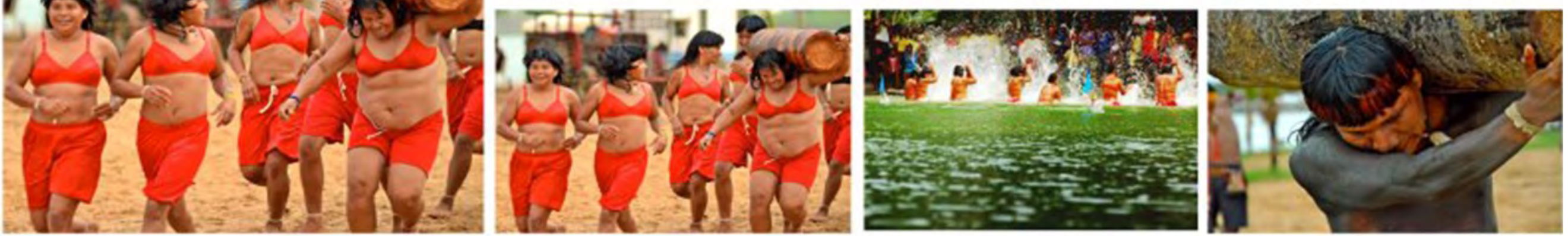